\title{
Medical isotope supply raises concerns
}

W

ill there be a medical isotope shortage when the National Research Universal (NRU) reactor in Chalk River, Ontario, stops production in October?

It's a multimillion dollar question. The last shortage in 2009, due to an NRU outage, cost an estimated \$5 million in Ontario alone.

While the federal government says that a "significant, prolonged disruption in the global supply that would affect patients" is "unlikely," the Organisation for Economic Cooperation and Development (OECD) and Canadian physicians are warning of a possible shortfall before new sources reach commercial production. To cover serious shortages, the NRU will be in "hot standby mode" until March 2018, CMAJ has learned.

It's a situation that worries Dr. Andrew Ross, the president of the Canadian Association of Nuclear Medicine. "One of my biggest concerns is the lack of transparency...."

Ross asked the previous federal government to establish a committee to ensure a stable isotope supply.

Previous outages of the NRU and other reactors supplying large proportions of the world's isotopes highlighted the chain's fragility, he said.

Supply currently relies on a few aging reactors around the world. At 58 years in service, the NRU is the oldest. It once produced around $40 \%-50 \%$ of the global supply of molybdenum-99, which accounts for about $80 \%$ of medical isotope requirements. Molybdenum-99 is purified to produce technetium-99m, used mainly in myocardial perfusion imaging, but also in bone and renal scans and other imaging.

In an email, Micheline Joanisse, a spokesperson for Natural Resources Minister James Carr, stated that the NRU's production has fallen to about $10 \%-15 \%$ of the world supply of molybdenum-99. The NRU also produces other specialized isotopes, including an estimated $85 \%$ of the world supply of medical-grade cobalt-60 for cancer radiotherapy.

Joanisse explained why the gov- ernment decided to stop NRU isotope production and eventually decommission the reactor. The federal government has always subsidized the NRU, but maintenance and operating costs have increased as the reactor aged. A heavy-water leak in 2009 cost the federal government $\$ 114$ million, and operations since 2008 have cost $\$ 351$ million. In addition, the reactor uses highly enriched uranium, which is being phased out worldwide under nuclear nonproliferation agreements, as it has potential for misuse in weapons.

Another major isotope reactor, OSIRIS in France, will go offline this year, according to a report by the OECD's Nuclear Energy Agency (NEA). After that, the NEA states, there may be problems meeting world demand in case of "adverse events" such as outages at major suppliers. A lot depends on when new sources become operational.

There is a window in 2017 and early 2018, before other sources are up and running, when supply will be tight, states the NEA report. The NEA is relying on the NRU being in a "hot standby mode" during this window in case of shortfalls, as "a useful stopgap."

Joanisse clarified that "hot standby" means that "production of molybdenum-99 could be resumed sufficiently rapidly to address a significant, prolonged shortage ... that would impact patients." But the government plans to restart production only if there is such a shortage.

"This is a worldwide problem. It's a very, very integrated system. When things go south, it will affect everybody," said Ross. "My biggest hope is that, over the course of the next six months, we can get the new federal government to understand this. If there is a system by which we understand that NRU will be able to start up again, the danger of supply problems will be majorly mitigated." - Carolyn Brown, Ottawa, Ont.

CMAJ 2016. DOI:10.1503/cmaj.109-5221 